\section{TIEMPO Y EDAD BIOLÓGICA ${ }^{1}$}

\author{
Esteban Vargas \\ Pontificia Universidad Católica de Valparaíso, Chile \\ esteban.vargas@ucv.cl \\ Ricardo Espinoza \\ Pontificia Universidad Católica de Valparaíso, Chile \\ respinoz@ucv.cl
}

Cómo citar este artículo/ Citation: Vargas, E.; Espinoza, R. (2013). Tiempo y Edad biológica. Arbor, 189(760):a022. doi: http://dx.doi.org/10.3989/arbor.2013.760n2008

Recibido: 29 mayo 2011; Aceptado: 7 septiembre 2012.

RESUMEN: En este trabajo intentamos meditar si es posible concebir la edad como un tiempo propio de los seres vivos incluyendo al hombre. En el trabajo revisamos diversos conceptos de edad obtenidos de diversas ciencias biológicas como la cronobiología, la gerontología, la biología evolutiva y la biología del desarrollo descubriendo que en ellas, en general, se sigue pensando el tiempo biológico como el tiempo que mide un reloj. Nosotros proponemos que la edad como tiempo biológico debe ser entendida como una fase del proceso biológico, pero en función del ciclo completo del organismo. En el caso del ser humano, su edad está determinada también por lo que se "espera" de él. Su edad está determinada entonces por aspectos biológicos y culturales.

PALABRAS CLAVE: Tiempo biológico; edad; tiempo cronométrico; envejecimiento.

Se podría afirmar, no sin razón, que el tiempo es uno de los grandes temas de nuestra época. Así, por ejemplo, en la ciencia física, Einstein actualizó el tema, en su Teoría de la Relatividad, al entender el tiempo como una función cuantificable entre el reloj y el observador, y no como algo absoluto (cf. Espinoza, 2009). Quedó identificado así el tiempo físico con el tiempo del reloj o cronométrico. Es la visión más predominante en la física aunque no es la única ya que,
Copyright: (C) 2013 CSIC. Este es un artículo de acceso abierto distribuido bajo los términos de la licencia Creative Commons Attribution-Non Commercial (by-nc) Spain 3.0.

ABSTRACT: In this paper we attempt to think if it is possible to conceive age as a characteristic time of living organisms including man. In the paper we review several concepts of age coming from sciences such as chronobiology, gerontology, evolutionary biology and developmental biology, and trough all of them, we see that biological time is thought as time measured by a clock. We propose that age as biological time must be understood as a phase in the biological process, but depending on the complete cycle of the organism. In the case of human being, his age is determined also by what is "expected" about him. His age is then determined by biological and cultural aspects.

KEYWORDS: Biological time; age; chronometric time; aging.

más recientemente, Prigogine $(1997,30)$ ha entendido el tiempo más bien por su carácter de irreversibilidad y creatividad que por su carácter de medida. Es un problema que la ciencia física tendrá que resolver. Pero el tema del tiempo no es privilegio de los entes físicos. También ha existido un gran número de importantes investigaciones sobre el tiempo en procesos relativos al hombre. Se habla así del tiempo de la conciencia (James, Bergson, Husserl), el tiempo histórico 
(Dilthey), el tiempo del proyecto (Heidegger), etc. El tiempo físico (cronométrico) y el tiempo humano han sido dos de los momentos centrales en la investigación del tiempo, aspectos aparentemente difíciles de conciliar.

En otras ciencias naturales hoy también se habla sobre el tiempo como, por ejemplo, el tiempo químico, geológico y biológico. En estas ciencias hay que meditar de qué manera estos tiempos pueden reclamar para sí un carácter propio, distinto de la conceptuación del tiempo más afín a la física actual, el tiempo cronométrico. En esta investigación nos aventuramos a tratar sólo del tiempo propio de los seres vivos, el tiempo biológico que llamamos "edad". Éste será nuestro tema. No nos proponemos averiguar en qué consiste el tiempo como tal (esto en general ha sido investigado en detalle), sino que intentamos vislumbrar, si existe, un tiempo propio de los procesos biológicos en tanto tales.

Ahora bien, hay que tener en cuenta que la edad, como tiempo biológico, ya ha sido levemente vislumbrada por el filósofo Xavier Zubiri (2008, 254). Sin embargo, su trabajo, profundamente inspirador para este escrito, quedó sólo en un mero proyecto sin haberlo desarrollado plenamente ${ }^{2}$. Por otra parte, el tema del tiempo biológico aparece también ricamente investigado en algunas ciencias como la gerontología, la psicología, la biología evolutiva, la biología del desarrollo, las ciencias cognitivas, la antropología, etc. Lo que hay que tratar de meditar es si su conceptuación, como decíamos, no es otra cosa que la del tiempo cronométrico.

Para entender lo que es el tiempo como edad nos será útil, ante todo, distinguirlo de otros conceptos de tiempo biológico que han ido apareciendo en algunas de las ciencias biológicas. Esto permitirá perfilar mejor el tema. Sólo entonces estaremos en condiciones de meditar si la edad puede ser un tiempo propio de los seres vivos.

\section{I- ALGUNOS CONCEPTOS DE EDAD EN LAS CIENCIAS BIOLÓGICAS}

\section{1) Edad y tiempo cronométrico}

Por tiempo cronométrico entendemos aquí el tiempo como "medida" del reloj. Es lo que Heidegger (2000, 310) llamó el tiempo vulgar, es decir, lo que generalmente todos entendemos por tiempo. ¿Cómo un reloj mide el tiempo? Se trata básicamente de poner en "relación de simultaneidad" dos procesos físicos en tanto sucesivos, como ya lo anunció Einstein (1984, 24-26). El tiempo no es, por tanto, una propiedad del reloj como su color o forma. Se trata entonces de poner en relación dos procesos. ¿Cuáles son estos dos procesos?
El primer proceso es el del reloj mismo. Un buen reloj, para la ciencia física, posee diversas fases sucesivas, pero éstas deben ser equidistantes, es decir, que la "distancia temporal", por ejemplo, entre un segundo y otro debe ser la misma. Ciertamente, en la Teoría de la Relatividad los segundos pueden alargarse o contraerse, pero esto ocurre sólo en unos relojes considerados en función de otros, bajo ciertas condiciones que no es del caso exponer aquí. Cada momento del proceso es, entonces, una fase y el tiempo medido es la "distancia" temporal entre una fase y otra. En los relojes usuales, además, su numeración es cíclica o periódica lo que parece imitar al comportamiento de los procesos astronómicos. No es de extrañar, entonces, que los primeros relojes usados sean precisamente los astronómicos como el día, el mes lunar, etc. Sin embargo, no es necesario que ello ocurra, ya que un cronómetro digital puede medir el transcurrir no cíclico, por ejemplo, en segundos. El segundo proceso es el ente físico que se va a medir. Lo que hacemos es poner en relación de simultaneidad las fases del proceso del reloj con las del ente físico en cuestión. Lo medido es justamente el tiempo cronométrico (una hora, veinte minutos, etc.). Como la observación de lo que es simultáneo es "relativa" al observador, entonces, se dice que el tiempo es relativo ${ }^{3}$. Ciertamente, el tiempo de la física no requiere necesariamente de un reloj; basta con la relación de dos procesos. Lo que sucede es que "mediante el uso del reloj, el concepto de tiempo se hace objetivo" (Einstein e Infeld, 1984, 135).

Ahora bien, todo esto puede usarse para medir el tiempo de los procesos biológicos. De un lado, ponemos el reloj y del otro, el proceso biológico en cuestión, como si fuera un cierto tipo de biyección. Si consideramos la distancia temporal de un organismo desde una fase a otra, a esto es a lo que se le llama "edad cronológica", que debería llamarse mejor "edad crono-métrica". Así, si una persona tiene treinta años, estamos queriendo decir que desde que nació hasta hoy, la Tierra (que hace de reloj) ha dado treinta veces la vuelta al Sol (suponiendo el Sol como centro del movimiento terrestre).

Pues bien, hay que señalar que esta edad cronométrica no es la edad biológica. La biología (por ejemplo, Kirkwood, 2000, 36) ya ha intuido esta distinción aunque, en general, no la ha conceptuado en forma precisa. La diferencia está en que las fases de un proceso biológico no poseen la misma cualidad o índole que las fases de un proceso físico en tanto que meramente sucesivo. En biología, las fases están determinadas por la dinámica del "proceso mismo" y no en función de las fases de un proceso físico externo (reloj). Así, por ejemplo, si tenemos varias fases en el 
organismo (a una fase "A" le sigue una " $B$ ", a ésta una " $C$ ", etc.), la determinación de cada fase no se realiza por su distancia cronométrica (como, por ejemplo, si se dijera que el proceso biológico se divide de suyo en fases regulares de un mes), sino por las determinadas "cualidades" que presenta la dinámica del sistema. De hecho, las fases de un ser vivo no son equidistantes como las de un reloj, sino que están a distintas distancias cronométricas que, además, pueden variar entre los individuos de una misma especie.

En fin, todo esto nos permite aproximarnos a un concepto de edad biológica. Para mayor claridad de lo ya dicho, se puede intentar aclarar una mala conceptuación en la conocida "paradoja de los gemelos", donde se confunde edad cronométrica y biológica. En este conocido experimento mental dos gemelos sincronizan sus relojes y uno de ellos parte de la Tierra a una velocidad próxima a la velocidad de la luz y vuelve unos años después. Una interpretación relativista (Hawking, 1988; Davies, 1996) nos dice que el gemelo viajero al volver a la Tierra sería "más joven" que el otro gemelo que se quedó en la Tierra. Paul Davies sostiene al respecto lo siguiente: "Es importante darse cuenta de dos cosas. Primera, el efecto de los gemelos es un efecto real, no sólo un experimento mental. Segunda, esto no tiene nada que ver con el efecto del movimiento sobre el proceso de envejecimiento" $(1996,60)$. Aquí se destaca que este experimento no es meramente mental, sino que hay que entenderlo como algo que, si se pudiera hacer, ocurriría efectivamente. Además, se nos remarca que esta explicación física no tiene relación de causa-efecto con los procesos propios de los seres vivos como el envejecimiento. En este escrito no vamos a discutir si es verdad que el gemelo viajero es más joven que el que se quedó en la Tierra. Todo ello es un problema de la física. Suponiendo que eso "sea cierto", lo que hay que averiguar es en qué "notamos" que el gemelo viajero es más joven que su hermano. ¿Notamos aquello acaso porque miramos sus relojes y descubrimos que uno de ellos indica menos tiempo que el otro? Desde luego que no. Decimos que uno es más joven que otro porque notamos que el más joven "presenta" caracteres biológicos que así lo identifican. La razón por la cual uno es más joven que el otro no está, pues, en la mera "medida" de sus relojes (edad cronométrica), sino en los caracteres biológicos que "posee". Esto nos pone en la pista de lo que buscamos.

\section{2) Edad y ritmos biológicos}

En el organismo encontramos diversos procesos que se repiten periódicamente con un patrón similar, es decir, que son cíclicos (Koukkari y Sothern, 2006). La "duración" de cada periodo es el tiempo que concibe la cronobiología. Esta ciencia estudia, en rigor, procesos biológicos que están determinados por "un ritmo interno autónomo y una perturbación periódica externa" (Montero y Morán, 1992, 278). Los diversos ritmos pueden entonces sincronizarse con las perturbaciones externas. Es lo que ocurre en los ritmos circadianos (aquellos que duran aproximadamente un día) como, por ejemplo, el ciclo sueño/vigilia, el ciclo de la temperatura corporal, etc. Si estos procesos son colocados en oscuridad, entonces el organismo repite más o menos el mismo periodo lo que demuestra que estos ritmos son en cierta forma autónomos de las perturbaciones ambientales, en este caso, del ciclo de la luz. Lo que la luz hace es más bien sincronizar los diversos ritmos. Como a todos los diversos ritmos no les llega la luz se requiere un ritmo maestro que los coordine. Esta función, en el hombre, parece ejercerla el núcleo supraquiasmático (NSQ). Ahora bien, hay que atender a que la periodicidad de estos ritmos, aunque sincronizable con los procesos externos, está determinada por los procesos biológicos mismos. De esta manera, si medimos la duración de cada periodo tendríamos, entonces, el tiempo como "ritmo biológico". Es un tiempo que, aunque medible con el tiempo del reloj, no está determinado por él. Se puede usar la duración de cada período como un tiempo propio. Por ello, se habla muchas veces de relojes biológicos (Gruart et al, 2002, 127). Existirían muchísimos relojes biológicos aunque uno de ellos (o más de uno) haría, tal vez, el papel de sincronizador. Es la función que tendría el NSQ. El tiempo como ritmo, como reloj biológico, nos muestra un tiempo propio de los procesos biológicos, en el cual, los periodos están determinados por la dinámica misma del proceso. Sin embargo, este tipo de tiempo no es edad por dos razones. Por una parte, este tiempo se refiere "casi" exclusivamente a subprocesos aislados dentro del organismo como los relojes celulares. No parece haber un reloj propio del organismo como totalidad (una especie de hora oficial del organismo), sino que existe, a lo sumo, un conjunto de relojes más o menos sincronizados entre sí. La edad, en cambio, se refiere a una cualidad temporal del organismo entero o, al menos, a una relación intrínseca de sus subprocesos. Por otra parte, y como distinción más importante, la cronobiología lo que en verdad piensa "como tiempo" es la duración del periodo medido en unidades de reloj (horas, días, etc.). Un reloj biológico no es otra cosa que otro tipo de reloj físico con la diferencia que sus periodos o ciclos no son completamente regulares en relación al reloj físico. El tiempo como "ritmo biológico" sigue siendo entendido como un tiempo cronométrico. Pese a todo esto, esta concepción nos va acercando más a lo que intentamos meditar.

\section{3) Edad y envejecimiento}

Decíamos antes que lo propio de los ritmos biológicos es su carácter más o menos cíclico. Pero hay dos tipos de procesos cíclicos en los seres vivos. Por una 
parte, ya lo hemos visto, tenemos los procesos que estudia la cronobiología. Son subprocesos que, en general, pueden reducirse a una célula o a un conjunto de ellas dentro de un organismo. Pero, por otra parte, existe un proceso cíclico del organismo mismo, no de sus subprocesos. Es lo que se llama el "ciclo de vida". Sin embargo, esto requiere ser meditado. Si pudiésemos ver la sucesión de fases de un organismo "individual" no notamos, en general, una repetición de ellas. Por ejemplo, a la juventud sigue la vejez, pero no suele suceder lo contrario y menos en forma periódica. Para entender el ciclo de la vida es menester poner atención a una distinción que se da con mayor claridad en la mayoría de los organismos pluricelulares. Hay que distinguir, tal como ya lo anunció Weismann (1889, 28), entre la línea germinal y la línea somática de un organismo. La línea germinal o reproductiva se refiere a las células de un organismo que pueden pasar de padres a hijos como espermatozoides y óvulos. En general, las células germinales son aquellas que pueden generar otras células, pero en tanto que esas células puedan constituir un nuevo organismo. En este sentido, las bacterias son células germinales. Ahora bien, si pudiésemos asistir al comienzo de la vida veríamos que una célula germinal va engendrando a otras hasta hoy. Desde luego, hay muchísimas células germinales que han muerto, pero hay una línea que ha sobrevivido, razón por la cual, se podría sostener (Holliday, 2007, 37), que es una especie de potencial línea inmortal, al menos hasta hoy. Por otra parte, están las células somáticas, las células no germinales. Estas células somáticas pueden dividirse y podemos descubrir también una "línea" somática de descendencia, pero no pueden, por sí solas, generar otro organismo. Son la inmensa mayoría de las células de nuestro cuerpo. Esta distinción entre línea germinal y somática, le permitió a Weismann discutir la teoría de la herencia de los caracteres "adquiridos" de Lamarck y de los neolamarckianos. Para nosotros, lo importante aquí es destacar que es esta línea germinal la que permite la continuidad de unos organismos a otros en el tiempo. Sólo desde esta perspectiva comparece, ante nosotros, el ciclo de vida de un organismo.

Ahora bien, hay una rama de la biología que ha tomado esta perspectiva desde el punto de vista del tiempo. Es la biología del envejecimiento o senescencia. Es de interés de gerontólogos y biólogos evolutivos. Se trata de explicar las "causas" del envejecimiento. Como sostienen Gavrilov y Gavrilova (2002, 341), la biología del envejecimiento es, en el fondo, una explicación de la teoría de "historia de vida", la cual piensa la evolución de los ciclos de vida desde el punto de vista de las restricciones energéticas. No es nuestro interés desarrollar aquí la explicación de la biología del envejecimiento, sino la concepción implícita que hay en ella de tiempo y edad. No obstante ello, y para perfilar mejor el tema, hay que distinguir, siguiendo a Rose (1991), dos tipos de explicaciones del envejecimiento. En primer lugar, hay una explicación "fisiológica". Se busca en la célula o en el organismo las causas próximas del envejecimiento como el desgaste de materiales, acumulación de radicales libres, fallas en los mecanismos de reparación del ADN, etc. Por otra parte, está la explicación "evolutiva". Ya no se pregunta "cómo" sino "por qué" se envejece. Esta pregunta tiene sentido si se cree que el envejecimiento no es algo que se da en todos los seres vivos. Por ejemplo, para la biología evolutiva del envejecimiento, un organismo como la hidra ciertamente muere, pero no envejece ya que "carece de una clara separación de la línea germinal y somática y no exhibe un evidente signo de intrínseca senescencia" (Kirkwood y Austad, 2000, 234, trad. nuestra). En esta concepción no es lo mismo muerte y envejecimiento (o senescencia). Volveremos pronto sobre ello. Aquí es pensado el envejecimiento como una especie de fenotipo que evoluciona. De hecho, se piensa que el envejecimiento comienza cuando ocurrió en los organismos la separación entre su función germinal y somática. La bacteria, como vimos, es una célula germinal por lo que no envejecería. Lo mismo ocurriría a la hidra que si bien es pluricelular, no posee una distinción precisa entre su función somática y germinal. Cada célula suya, en general, puede originar a otro organismo. Hay dos teorías evolutivas, no excluyentes entre sí, que pueden explicar el envejecimiento; la teoría de la acumulación de mutaciones y la teoría de la pleiotropía antagonista (Rose, 1991, 62; Charlesworth, 2000, 928). Ambas teorías pretenden explicar la eficacia biológica de los genes según el tiempo en que se expresen. Si hay genes deletéreos que se expresan en edades tempranas el organismo prácticamente no dejará descendencia y tales genes tenderán a desaparecer de la población. Pero si hay genes deletéreos que se expresan en edades tardías, el organismo ya habrá podido dejar descendencia y pasará esos genes a la generación siguiente. Esto incluso si es un gen letal. Imaginemos que alguien posee un gen cuya letalidad se expresa a los sesenta años. Esa persona morirá en esa edad cronométrica sí o sí. Pero esa persona, para ese entonces, ya habrá podido dejar descendencia con lo que pasará sus genes a la generación siguiente. La selección natural actúa negativamente eliminando genes deletéreos o letales que se expresen en edades tempranas, pero prácticamente no actuará si tales genes se expresan en edades tardías. Las dos teorías antes mencionadas se hacen cargo de esta concepción acentuando un matiz u otro. Hay incluso otra teoría, la del "soma perecedero" de Kirkwood (2000, 77-93) que, de algún modo, incluye a las otras dos. Nos dice que el envejecimiento es resultado de una transacción energética entre lo que invierte un organismo en su función germinal y en su función somática. Lo que sucede es que no es ventajoso invertir toda la ener- 
gía en la reparación somática ya que el organismo de todas maneras muere. Esto podría perjudicar su desarrollo germinal o reproductivo.

Como ya hemos señalado no es nuestra intención explicar aquí los problemas de la biología del envejecimiento en su momento fisiológico y evolutivo. Lo que es interesante destacar es que ambas explicaciones siguen pensando el tiempo biológico como "cronométrico" a pesar de usar explícitamente el concepto de edad. Lo importante es aquí meditar qué concepto de tiempo y edad existe en estas ciencias. Hay dos conceptos de envejecimiento en los que comparece implícitamente una determinada concepción de edad biológica. Veámoslos separadamente.

\section{a) Concepto demográfico de envejecimiento: la edad a nivel poblacional}

Una primera manera de definir el envejecimiento es considerándolo como el incremento en la tasa de mortalidad de una población en el tiempo. A medida que los organismos van viviendo se acercan cada vez más a su muerte. Tomado esto en términos "poblacionales" se puede intentar medir la tasa o patrón de mortalidad, según sus diversas edades cronométricas. Cada población tiene su patrón definido. Una población que no presente un incremento en la tasa de mortalidad se dice que no envejece. Es el caso de la hidra. No se trata que las hidras no mueran, todas lo hacen al fin y al cabo. Se trata que su tasa de mortalidad no incrementa mayormente, es relativamente constante. Sólo en este sentido se sostiene que envejecimiento y mortalidad no son lo mismo. A esta definición demográfica o poblacional se le pueden agregar más determinaciones como la disminución en la tasa de fecundidad. En el fondo, se puede definir el envejecimiento como "una persistente declinación en los componentes de la eficacia biológica (fitness) de un organismo, a una edad específica, debido a un interno deterioro fisiológico" (Rose, 1991, 38, trad. nuestra). Esta definición es la que usa la biología evolutiva y también algunos gerontólogos. Permite obtener un dato "objetivo" que permite comparar diversas especies sin apelar a complicadas distinciones fenotípicas para reconocer el envejecimiento. Ahora bien, ¿cuál es el concepto implícito de edad y de tiempo que existe en este concepto demográfico de envejecimiento? Ante todo, la medición de las tasas de mortalidad se ha hecho en función de la edad cronométrica. Esto quiere decir que las fases del proceso biológico del organismo están determinadas por las fases del reloj (horas, días, años, etc.). Recordemos que nosotros buscamos que las fases o edades del organismo estén determinadas por el proceso biológico mismo. Este concepto nuestro choca naturalmente con el de la biología del envejecimiento. Aquí se piensa la edad como la fase cronométrica en la cual el organismo queda determinado en función de una tasa de mortalidad. A propósito de esto, hay que destacar que el envejecimiento podría pensarse de otra manera. Puede pensarse como una especie de sucesión "cualitativa" de edades. Envejecimiento no sería aumento de probabilidad de muerte, sino un pasar de unas edades a otras, una especie de "edadear", si se nos permite la expresión. Volvamos al caso de la hidra. Desde el punto de vista del envejecimiento demográfico este organismo no envejece. Por ello, no tendría edad, no en el sentido en que no la podamos poner en correspondencia con un reloj, sino en el sentido en que ninguna de sus edades cronométricas ofrece diferencias significativas en lo que dice relación a su tasa de mortalidad. Ello no ocurre en nuestro concepto de envejecimiento como "edadear". La hidra ofrece distintas edades, pues, posee diversas fases intrínsecas de desarrollo y por ello "edadea"

Por otra parte, en estas investigaciones se utiliza la edad cronométrica de una población, no de un organismo individual. Ello porque determinamos las edades en función de la tasa de mortalidad, concepto sólo aplicable a una población en sentido estadístico. Nosotros buscamos conceptuar la edad como una "especie" de carácter que surge del organismo individual y no de un mero promedio estadístico. Ahora bien, tomando los índices de mortalidad de una población (por ejemplo, humana o de insectos de laboratorio), Rose $(2004,22)$ ha podido apreciar tres fases de mortalidad ${ }^{5}$, que podríamos considerar como edades. En la primera edad no habría un aumento significativo de la tasa de mortalidad. En la segunda edad habría un rápido ascenso y en la tercera edad, tal tasa se mantendría constante. En esta tercera edad no habría envejecimiento, según el concepto demográfico. Esta concepción de edad como "fase de mortalidad" es muy interesante porque tal concepto no queda determinado exclusivamente por la edad cronométrica, sino por el patrón de mortalidad. La edad cronométrica es siempre creciente, cosa que no ocurre en este nuevo concepto de edad. Esta idea se acerca bastante a lo que buscamos. Lamentablemente, incluso con esta precisión, tal concepto de edad sería obtenido desde un aspecto poblacional estadístico y no individual.

\section{b) Concepto fenotípico de envejecimiento: la edad como expresión de un biomarcador}

Hay otro concepto de envejecimiento que busca encontrar caracteres fenotípicos de envejecimiento, pero en el individuo. Es el concepto que más se usa en la gerontología. Para ello, se usa un indicador llamado "biomarcador", cuya función indique la edad y el envejecimiento. Se puede usar, por ejemplo, el color del pelo. Pero esto no es muy cuantificable, así que se usan múltiples biomarcadores como el desgaste de huesos y dientes, concentración de enzimas, longitud 
de telómeros, etc. ¿Cómo se piensa la edad y el tiempo desde este concepto?

Ante todo, se eligen estos biomarcadores porque se sabe que indican, "en la población promedio", la edad biológica. Así, por ejemplo, se toma como indicador de vejez un determinado desgaste de los dientes. Por ello, el biomarcador no es lo que indica la edad biológica, sino al revés; porque sabemos que nos encontramos en una edad biológica determinada usamos tal o cual biomarcador. Otro problema de esta concepción es que se elige un biomarcador que pueda cuantificarse. Esa cuantificación se puede, a su vez, poner en correspondencia con la edad cronométrica, con lo cual, el biomarcador termina siendo, en el fondo, un indicador de edad cronométrica y no biológica. Pero no hay que olvidar que porque ya sabemos identificar una edad biológica, sólo por ello podemos elegir un biomarcador determinado. Estos biomarcadores son, en general, funciones crecientes como la edad cronométrica. Esto nos muestra el envejecimiento como algo que "inexorablemente siempre va ocurriendo". Aquí se entiende el organismo como un "objeto" que se va desgastando. Pero esto ocurre sólo por su relación con la edad cronométrica cuyo tiempo "siempre corre". Por último, el biomarcador indica la edad biológica de un individuo, pero en función de la edad biológica "promedio" de una población. Por ello, en el fondo, el biomarcador determina la edad poblacional promedio igual que la concepción demográfica.

En definitiva, la biología del envejecimiento (evolutiva y fisiológica) nos ha mostrado dos conceptos de envejecimiento, poblacional y fenotípico, los cuales, nos manifiestan dos conceptos de edad. A pesar de las diferencias, se entiende el envejecimiento como un proceso en el tiempo, pero en el tiempo cronométrico, lo cual no permite entender bien el proceso de envejecimiento, como lo ha señalado también Baars $(2006,3)$. No obstante ello, tales conceptos nos han acercado aún más al problema de la conceptuación de la edad como tiempo biológico.

\section{4) Edad y desarrollo}

Los seres vivos se caracterizan por ser estructuras procesuales, es decir, por estar en constante cambio. A este carácter del organismo es a lo que llamaremos, en general, "desarrollo". Estos procesos poseen diversas fases o etapas como la segmentación, la gastrulación y la organogénesis. En el organismo ya nacido, y en especial en el hombre como veremos, encontramos otras fases como la infancia, pubertad, adultez, vejez, etc. A todas estas fases, y en especial a las del organismo ya nacido, son las que llamamos "edades". Edad es así sinónimo de fase del desarrollo. Ahora bien, en biología del desarrollo se suele entender el tiempo no como edad, sino como la "distancia" temporal entre una fase y otra. Así, si se comparan las es- pecies en sus relaciones filogenéticas pueden encontrarse diferencias en los tiempos de desarrollo somático y reproductivo. Es lo que se llama "heterocronía" (Ridley, 2004, 576). El tiempo biológico del desarrollo sería así la "distancia temporal" entre una fase y otra. Pero aquí es fácil darse cuenta de que esa distancia temporal no es otra cosa que una medida de tiempo cronométrico que funciona como tiempo absoluto desde el cual se pueden medir las diferencias relativas entre los tiempos de desarrollo de las especies. Por ello, para eliminar esta dificultad, podría tomarse el "cuociente" entre las duraciones cronométricas de las diversas etapas o fases de desarrollo. Esto genera una magnitud que es adimensional y que mide, en el fondo, la "distancia temporal relativa" entre las fases en el desarrollo. Es la idea que ha desarrollado Detlaff $(1995,86-90)$. Así, por ejemplo, si tenemos varias fases en el desarrollo de un organismo, más importante que medir sólo sus distancias cronométricas, lo interesante es medir sus distancias "relativas", sus cuocientes. Ello ocurre porque la distancia cronométrica entre las fases no es homogénea, puede cambiar por muchas razones, por ejemplo, por la temperatura. Pero la relación o cuociente entre las fases es más o menos homogénea y puede revelar lo propio de una especie en comparación a otras, lo que permite conceptuar mejor las heterocronías. Esta idea es brillante y merecería seguirse pensando. Ignoramos si se ha expandido a otras ramas de la biología. En ella, se piensa el tiempo biológico como algo, en cierta forma, distinto del tiempo cronométrico, a saber, como una "relación" entre las "sucesiones cualitativas" de fases o edades, lo que antes llamábamos "edadear". Las fases o edades se suceden unas a otras y en esta distancia temporal relativa estaría su carácter temporal. Aquí ya podríamos decir que tenemos una conceptuación del tiempo biológico como algo distinto del mero tiempo cronométrico de la física. No obstante ello, en esta concepción se sigue tomando, en el fondo, el carácter temporal del proceso biológico como una "sucesión cronométrica" de fases o edades, razón por la cual siempre tiene que usarse el reloj para la determinación de las distancias relativas. Se piensa, en el fondo, edad y tiempo como cosas distintas. Pero cabe la posibilidad de pensar la edad como un carácter propiamente temporal. Es la vía que ensayaremos. No obstante ello, los pasos anteriores, sin duda, nos han acercado todavía más a esta vía.

\section{II- ¿QUÉ ES EL TIEMPO COMO EDAD BIOLÓGICA?}

Hasta ahora hemos buscado en algunos campos del saber biológico un concepto de edad como tiempo "propiamente" biológico. El camino recorrido nos ha llevado a mostrar qué es lo que no entendemos por edad. Pero, junto con ello, se nos ha abierto un camino positivo que ahora tenemos que transitar en 
mayor grado. Por ello, las repeticiones son inevitables. Así, por una parte, buscamos el tiempo como edad mirando al ser vivo como un Todo, como un organismo. Es allí donde tenemos que dirigir la mirada. Por otra parte, buscamos en el organismo qué aspecto de él nos manifiesta su edad y su temporalidad. Estos dos puntos son los que hay que precisar ahora.

\section{a) Organismo y edad}

Ante todo, debemos meditar a qué organismo le aplicamos más inmediatamente las cualidades "etarias" de juventud, adultez, vejez, etc. Sin duda, ese organismo es el hombre. En él, sin conocer las grandes teorías biológicas ya mencionadas, reconocemos tales cualidades. Las reconocemos mirando el conjunto, no tal o cual aspecto. Así, una persona de cualidades juveniles, pero con el pelo cano, no por ello es calificada de vieja. Hay que mirar una serie de rasgos relacionados como un Todo, no aisladamente. Estos rasgos no son solamente los llamados biológicos, sino también mentales. Hay así una edad biológica y mental. Éste es el fenómeno más inmediato de la edad como tiempo. De aquí arranca toda conceptuación de la edad como tiempo, aplicable no sólo al hombre, sino al resto de los seres vivos, dado que éstos nos manifiestan ciertos fenómenos semejantes al hombre ${ }^{6}$. La riqueza del concepto es la que nos abrirá o no las diversas posibilidades de comprender el fenómeno de la vida en su aspecto temporal. Ahora bien, hay que tener en cuenta de que los organismos son más o menos semejantes los unos a los otros estableciéndose diversos grados de parentesco. A esta propiedad de relación intrínseca entre organismos es a lo que llamaremos "biodiversidad". Hay que pensar la edad en toda su biodiversidad y no como un concepto aplicable por igual a todos los organismos. Es lo que sucede en los conceptos de edad anteriormente mencionados. Existirá edad en algunos o en todos ellos (y además en diversos grados) según la riqueza del fenómeno que vamos a estudiar. Para ello, consideremos, por una parte, que hay organismos constituidos por una sola célula como las bacterias y amebas. Habría que meditar si en ellos existe una "edad biológica". A simple vista, se ve muy difícil, por ejemplo, que una bacteria sea "joven" en sentido biológico y no puramente cronométrico. En el mismo caso se encontrarían las células individuales que constituyen un organismo pluricelular cuya edad es vista, en general, sólo en función de sus propios procesos celulares. Por otra parte, tenemos los organismos pluricelulares concebidos como algo "más" que un conjunto de células. Aquí hay una gran diversidad de organismos como los álamos, las hidras, los perros, etc. Un concepto clarificador debería considerar todos estos aspectos. Con todo ello en mente, intentemos meditar en qué consiste el carácter de edad como tiempo.

\section{b) Edad y carácter procesual}

Decíamos, en la primera parte, que los procesos biológicos de un organismo poseen fases intrínsecamente cualificadas. Cada fase es lo que llamamos una edad. Por tanto, un primer problema es pensar en qué consiste cada "fase" del proceso biológico. Por otra parte, la edad como tiempo no es la mera cualidad de cada fase. Podría pensarse entonces que como las edades pueden "sucederse" las unas a las otras, su carácter temporal estaría en esa mera "sucesión", en ese "edadear". Sería una sucesión cualitativa y no puramente cronométrica o cuantitativa (tiempo cronométrico) la cual ya hemos descartado en la primera parte como carácter propio de la edad como tiempo biológico. No obstante ello, esto tampoco parece ser exactamente el tiempo biológico como edad. No todo tiempo tiene la estructura de una sucesión, como ya lo ha anunciado Zubiri siguiendo la tradición de la fenomenología ${ }^{7}$. Es desde esta tradición desde donde intentamos pensar el tiempo biológico. Lo propiamente temporal, en este caso, no está en la mera sucesión, sino en la "apertura" de cada fase entendida como etapa temporal. Hay que explicitar mejor estos dos puntos.

\section{b.1) La edad como fase}

Decíamos que una de las propiedades fundamentales de los organismos es su desarrollo. Éste se caracteriza, ante todo, por ser un "crecimiento". Como las células, por paradójico que ello suene, se "multiplican" por "división", su reproducción continua haría que tales células se irían haciendo cada vez más pequeñas hasta desaparecer. De aquí entonces que las células que han sido viables, dado su tipo de reproducción, son las que manifiestan "crecimiento". Es una propiedad del desarrollo de todos los organismos viables, tanto unicelulares como también, por extensión, de los pluricelulares, ya que éstos crecen, en buena medida, por el crecimiento de sus células. Ahora bien, cada momento del crecimiento de un organismo puede ser considerado una "fase". No es algo puramente cuantitativo, pues, está determinado por toda la dinámica del organismo en cuestión. Piénsese, por ejemplo, en las fases o etapas de crecimiento de un insecto. Sin embargo, el crecimiento, por sí solo, no explica una fase del desarrollo. Ello ocurre porque el crecimiento no es la única propiedad del desarroIlo. Hay otra propiedad, que se apoya en la anterior, que es la "diferenciación celular". Esta diferenciación se la entiende en biología del desarrollo, ante todo, como aquel proceso por el cual una célula da origen a otras células de distinto tipo que la progenitora. Esto ocurriría en los organismos pluricelulares. Pero puede considerarse esta diferenciación también como un proceso que ocurre "intracelularmente". De esta manera, podrían existir fases del desarrollo si consi- 
deramos los diversos momentos por las cuales la célula se va diferenciando "internamente". Sería el caso de lo que se ha llamado las "etapas del ciclo celular", que justamente toma en cuenta la diferenciación y el crecimiento. En el caso de los organismos unicelulares podría decirse, en sentido muy amplio, que poseen fases $y$, por tanto, edades. Difícilmente podrían ser calificadas, por ejemplo, de jóvenes, viejas, etc., pero tendrían una especie de "edad celular" en este sentido. Pero hay una tercera propiedad del desarrollo, propia de los organismos pluricelulares. Es la "morfogénesis" por la cual se "forman" y también "modifican" órganos y estructuras en general. No es algo, por tanto, que dure hasta la formación del embrión, sino toda la vida. Se apoya en las dos propiedades anteriores. Sin crecimiento ni diferenciación celular no habría morfogénesis. Ahora bien, habría que decir que el desarrollo del organismo posee diversos momentos o fases intrínsecamente cualificadas como la segmentación, gastrulación y organogénesis. Son fases del organismo $y$, por tanto, pueden considerarse como edades, según nuestro concepto. La determinación de estas fases, aunque no es unívoca, no es tampoco meramente arbitraria. Depende de los procesos internos del organismo considerado como un sistema. Hay que tener en cuenta que las fases más importantes en el hombre no son éstas (las que hemos sabido en épocas recientes), sino las que se manifiestan en el organismo "ya nacido". Aquí, su determinación sólo puede hacerse "a grandes rasgos", destacando color de pelo, forma de la piel, etc. Hay que también considerar caracteres mentales según las diversas culturas, etc. En el hombre la discriminación de una fase y otra, su límite, no es algo preciso, sino algo difuso. Lo mismo para el resto de los seres vivos. No obstante ello, puede detectarse, en líneas generales, una fase de otra. A esta fase la llamamos "edad". Sin embargo, esta denominación es aún imprecisa. Es lo que tenemos que aclarar ahora.

\section{b.2) La edad como "apertura" temporal de las fases}

Decíamos que el proceso de desarrollo del organismo posee una serie de fases o momentos que llamamos edades. Esto es todavía impreciso porque aún no hemos precisado el carácter "temporal" de esta fase como edad. Aquí hay dos aspectos que hay que aclarar. Su investigación nos dejará más patente la vía por la que se "podría" pensar la edad como tiempo.

Por una parte, podría pensarse que la edad como tiempo biológico del organismo radica en su mero carácter de ser "fase" del proceso biológico. Así, hemos dicho repetidas veces que fase es lo mismo que edad y que en ese carácter de edad radica el tiempo de lo vivo. Esto es parcialmente verdadero. Ello porque el carácter "etario" del organismo no consiste en su mero ser momento o fase del desarrollo. Para en- tender esto coloquemos un ejemplo imaginario. Supongamos que en un lugar recóndito descubrimos un nuevo organismo nunca antes visto. Nos preguntamos frente a él qué edad biológica posee. Disponemos de todo lo necesario para hacer múltiples estudios: análisis genético, estudio de la velocidad de su metabolismo, capacidad actual de reproducción, edad cronométrica, etc. Con todo ello, ¿̇podemos saber qué edad biológica tiene? Por supuesto que no. Estos estudios podrían darnos muchas propiedades positivas del tipo de proceso que el organismo posee actualmente, pero esto, por sí mismo, no nos ofrece exactamente su edad biológica. Esto ocurre, al parecer, porque no tenemos ante nosotros cómo serían las demás fases o etapas del "ciclo completo" de ese organismo. Ahora bien, el ciclo completo de un organismo como individuo no lo tenemos sino hasta su muerte. Lo que tenemos es el ciclo de varios organismos de una misma población o especie ya fallecidos. Este dato constituye el "horizonte" desde donde podemos determinar concretamente cada fase como edad. Para explicar esto, hay que identificar aquí tres estratos del proceso biológico, cada uno fundado en el anterior. En primer lugar, hay que considerar la fase como "momento" del proceso biológico. Es una propiedad o cualidad del proceso de desarrollo. Este aspecto es el único que podría, tal vez, detectarse en el ejemplo imaginario dado más arriba. En segundo lugar, hay que considerar la fase en tanto "tiempo", la cual no radica en el mero momento del proceso de desarrollo individual, sino en ese mismo momento, pero "en función de" los demás momentos. El tiempo biológico es así función, apertura de unos momentos a otros. Cada momento, en tanto fase temporal, lleva en sí mismo el momento anterior y posterior ${ }^{8}$. Así, por ejemplo, la juventud, como fase temporal, sólo puede entenderse desde la vejez y viceversa. He aquí el fundamento de la edad como cualidad "temporal" biológica. Pero esto es todavía insuficiente para aprehender "concretamente" la edad biológica del organismo. Tenemos que, en tercer lugar, dar un paso más. Recordemos que el proceso biológico de un organismo puede atenderse desde su "carácter cíclico", siguiendo su línea germinal. Aquí se patentiza el momento del proceso, pero en tanto que se repite. Desde este aspecto, cada fase, por ser apertura, puede determinarse en su "posicionalidad" precisa frente a otras fases. De esta forma, sólo con el ciclo de vida completo del organismo promedio en nuestro "horizonte" podemos precisar el "orden" normal en que cada fase se presenta en el organismo. Cada fase considerada "temporalmente" es ahora algo más que una mera fase de un proceso: es una "etapa" del organismo. Etapa es la fase del proceso biológico en tanto ordenada temporalmente en función del ciclo completo del organismo. Edad, en sentido amplio, es la fase entendida como etapa. Es lo que intentamos mostrar en el ejemplo del organismo 
desconocido. Su edad como etapa no puede ser aprehendida concretamente sino hasta que tenemos su ciclo completo. Hay que destacar que este horizonte, en rigor, sólo se manifiesta para el hombre. Esto no significa que la edad biológica sea algo subjetivo. La sucesión cualitativa de fases de un proceso biológico y su momento de apertura son propiedades del organismo. La "posicionalidad", el orden de una fase en función de otras (su carácter de "etapa") en el ciclo de vida tampoco es algo subjetivo, pero es dependiente de una cierta operación de atención de un determinado aspecto del proceso de desarrollo. Esta operación deja patente el ámbito temporal del ciclo de vida. Este ámbito se complica más en el caso de la edad humana, pues, su tiempo biológico se encuentra entretejido con propiedades biológicas, mentales y culturales, por las cuales, cada etapa del ciclo completo está determinada no sólo por lo que el hombre como organismo manifiesta, sino también por lo que "espera" de él. Se entreteje el tiempo biológico y el tiempo del proyecto humano, que tanto gustaba de pensar a Heidegger. Ser adulto, por ejemplo, no es sólo cuestión de poseer determinadas cualidades biológicas, sino que depende de nuestro proyecto social de vida, en este caso, de lo que nosotros esperemos de un adulto como el poseer bienes, determinada habilidad, etc. De hecho, sólo en el hombre la llegada a la adultez, entendida como etapa biológica, no coincide necesariamente con su maduración sexual.

Por otra parte, podría pensarse que el carácter temporal de los procesos biológicos se encuentra, no en la mera fase como edad, sino en la "sucesión" de las edades, lo que nosotros conceptuamos antes como "edadear". Esto en cierta forma es verdad, pero debe ser entendido correctamente. Ante todo, como hemos visto en la primera parte, el tiempo biológico no viene determinado por la mera "distancia temporal" entre fases sucesivas establecidas en correspondencia con las fases equidistantes de un reloj. El tiempo biológico no es una variable independiente o absoluta que corre por fuera de los procesos del organismo, sino que es dependiente de éstos. Ahora bien, decíamos que las fases de un proceso biológico se determinan por la dinámica misma del proceso. Por ello, puede pensarse que el tiempo biológico radica en la "distancia temporal cronométrica" entre las fases sucesivas. Tal tiempo sería muy "variable" ya que las fases pueden alargarse o contraerse según la dinámica del sistema. Así, por ejemplo, el tiempo entre la segmentación y la gastrulación puede modificarse por acción de la temperatura. Pero el tiempo biológico como edad no consiste tampoco en la mera sucesión cronométrica de fases o edades. Nuevamente sería entender el tiempo biológico desde algo externo (un reloj). El carácter temporal de la edad, como veíamos, radica en la intrínseca apertura temporal de unas etapas a otras en el ciclo completo del organismo. Estas etapas cier- tamente se suceden (lo que llamábamos "edadear"), pero su carácter temporal biológico no radica exactamente en su medida en años, sino en que estas etapas están colocadas intrínsecamente unas "después de" las otras. La juventud y la adultez como etapas, por ejemplo, no están determinadas simplemente por un determinado número de años transcurridos, sino por características procesuales por las cuales cada fase o etapa está abierta temporalmente a las demás. En este caso, la adultez es una etapa que está "despuésde" la juventud. Pero esto no significa que, en algún caso, algún organismo no pueda pasar de la adultez a la juventud. Esto no es imposible. Sólo el tiempo cronométrico corre inexorablemente hacia el pasado. Esto es lo que hace concebir el envejecimiento como un sufrir los desgastes del paso inevitable del tiempo. Pero ello no ocurre en el tiempo biológico como edad. Podría ocurrir un retroceso. No es necesario que ocurra, pero si ocurre, siempre sería un "retroceso" que presupone que la adultez es una etapa "después-de" la juventud, no como sucesión de fases cronométricas, sino en tanto etapa biológica.

Resumamos. La edad como carácter temporal propio del organismo no es una cualidad o contenido sensible de un organismo como el color de pelo, largo de los dientes, etc., ni siquiera considerado todos estos caracteres en conjunto. Por ello, en rigor, nunca se reducirá la edad a la magnitud de un biomarcador. La edad más bien apunta a todas estas cualidades de una fase del proceso biológico, pero en "apertura" temporal a las otras fases del ciclo completo y aquí radica la novedad misma de lo biológico. Estas fases se suceden (lo que llamamos "edadear"), pero su momento temporal biológico no radica exactamente en su medida en años, sino en que estas fases posean una posición determinada unas después de otras. En todo ello radica la dificultad de su concepción y precisión. No es algo tan fácil de describir como el color de pelo, pero tampoco es algo tan evanescente. Nuestra concepción de edad permite iluminar este aspecto del proceso biológico que otras concepciones provenientes de otras ramas de la biología no hacen. Hay que destacar que el hombre presenta una mayor complejidad en la conceptuación de su edad debido a que no sólo existen caracteres biológicos implicados, sino también hay caracteres mentales determinados culturalmente. Sin embargo, dentro de una sociedad está determinación se hace más "patente" dado que todos, más o menos, ya sabemos lo que se espera del ser humano en sociedad. Además, sólo entre nosotros son más patentes los caracteres biológicos procesuales. Por ello, en rigor, sólo en el hombre hay edad con mayor precisión. 
1 Este trabajo fue posible gracias a un proyecto FONDECYT Chile de Postdoctorado № 3085042 llamado “El problema del tiempo biológico desde el horizonte de la filosofía de Zubiri" y el Proyecto FONDECYT Chile № 1110507 Ilamado "Realidad y cuerpo en Zubiri" (Investigador Responsable: Dr. Ricardo Espinoza Lolas. Alumnos tesistas: Mg. Eugenia Colomer (eugenia.colomer@ucv.cl) y Mg. Ronald Durán (ronald.duran.a@ mail.pucv.cl)).

2 Para un detallado trabajo sobre el tiempo, a la luz del horizonte de la filosofía de Zubiri, pueden considerarse los trabajos de Espinoza (2007 y 2009) y su libro Realidad y tiempo en Zubiri (2006). Para un estudio sobre el problema del tiempo biológico en Zubiri puede consultarse a Vargas (2009). Estos trabajos delinean algunos de los supuestos en que transcurre esta investigación.

3 “... es muy interesante señalar que lo único problemático que tiene esta teoría es, a lo mejor, su nombre; llamarla 'relatividad' ha inducido a muchos errores a lo largo de los años. Algo como si Einstein habría dicho que: 'iTodo es relativo'! Pero esto es totalmente alejado de la verdad; por el contrario, lo que se está diciendo enfáticamente y con toda verdad es que: 'iTodo es respectivo'! Entender el término relatividad por respectividad ayudaría a priori a eliminar muchas falsas interpretaciones de esta teoría" (Espinoza, 2006, 267-268).

\section{BIBLIOGRAFÍA}

Baars, J. (2006): “Introduction: Chronological time and chronological age. Problems of temporal diversity". En J. Baars \& H. Visser (eds.), Aging and Time. Multidisciplinary Perspectives (Society and Aging). Amityville, NY: Baywood, 1-13.

Charlesworth, B. (2000): "Fisher, Medawar, Hamilton and the Evolution of Aging". Genetics 156, 927-931.

Davies, P. (1996): Sobre el tiempo. Barcelona: Crítica.

Dettlaff, T. (1995): “Clocks for studying temporal laws of animal development". En On the Way to Understanding the Time Phenomenon: the Constructions of Time in Natural Science. Part 1. Interdisciplinary Time Studies. World Scientific:
4 La investigación del envejecimiento, desde el enfoque gerontológico, es una investigación eminentemente práctica tendiente a conseguir la "inmortalidad" entendida como una disminución en las tasas de mortalidad. Pero aún dentro de este proyecto debiera importar no tanto el patrón de supervivencia o mortalidad, sino la retención de las edades más tempranas. ¿Quién querría vivir 800 años si 650 los vive con caracteres de edades mayores? La edad es algo más cualitativo que cuantitativo. Además, en el hombre involucra aspectos no puramente biológicos como lo que se espera de él. Depende de un proyecto de vida. La manera cómo se mide y entiende el envejecimiento debe ser repensada incluso para fines prácticos. No es el tema que nos interesa desarrollar en este trabajo.

5 Según Shostak (2006, 34-37), ya a comienzos del siglo XX, Karl Pearson, analizando las curvas de mortalidad del hombre, estableció cinco estados o edades que hoy se han ampliado a siete. La idea, por tanto, no es nueva.

6 Ésta no es una visión antropocéntrica de la edad ya que los demás organismos también nos son manifiestos en su carácter temporal. Sólo señalamos que el fenómeno de la edad se manifiesta primordialmente en la vida humana y que por extensión se postula al resto de los seres vivos.

Singapore, New Jersey, London, Hong Kong, 85-97.

Einstein, A. (1984): Sobre la teoría de la relatividad especial y general. Madrid: Alianza.

Einstein, A. e Infeld, L. (1984): La evolución de la física. Barcelona: Salvat.

Espinoza, R. (2006): Realidad y tiempo en Zubiri. Comares: Granada.

Espinoza, R. (2007): “En torno al problema del tiempo en la realidad humana". Pensamiento, Vol. 63, № 236, Universidad Pontificia Comillas de Madrid, Madrid, pp. 267-302.

Espinoza, R. (2009): “Tiempo y cosa: La influencia de Einstein en el pensamiento
7 Zubiri, por ejemplo, ha pensado el tiempo histórico como no puramente sucesivo, en el cual existen diversas "edades históricas" (2006, 161). Ello porque la historia no es un mero proceso de sucesión de eventos, sino de capacitación y generación de posibilidades. Así, dos sucesos pertenecen a la misma "edad histórica" no en tanto que simultáneos (tiempo cronométrico), sino en tanto pertenecen a la misma fase de un mismo proceso histórico de acontecer de posibilidades. Lo que ocurría "simultáneamente", por ejemplo, en Japón y Europa en el siglo VII d. c. pertenece al mismo tiempo cronométrico, pero no a la misma edad o tiempo histórico. De allí que, con razón, los historiadores nos hablen de distintas "edades" como la Edad Media, cuyas cualidades temporales jamás quedan expresadas en la mera duración en años. La clasificación de un suceso como perteneciente o no a una determinada edad histórica es asunto de historiadores y no de físicos.

8 La concepción del tiempo como poseyendo tres momentos indisolubles que imprecisamente podríamos llamar "pasado-presente-futuro" es algo que, aunque con diferentes matices, han sostenido filósofos como Husserl, Heidegger y Zubiri. Es desde este horizonte desde donde intentamos pensar las fases biológicas en su carácter temporal (cf. Espinoza, 2006). 
Holliday, R. (2007): Aging: The Paradox of Life. Dordrecht, The Netherlands: Springer.

Kirkwood, T. (2000): El fin del envejecimiento. Barcelona: Tusquets.

Kirkwood, T. y Austad, S. (2000): "Why do we age". Nature, 408, 233-238.

Koukkari, W. y Sothern, R. (2006): Introducing biological rhythms. New York: Springer.

Montero, F. y Morán, F. (1992): Biofísica. Madrid: Eudema.

Prigogine, I. (1997): El fin de las certidumbres. Santiago: Andrés Bello.
Ridley, M. (2004): Evolution. Boston: Blackwell Scientific Publications.

Rose, M. (1991): Evolutionary Biology of Aging. New York: Oxford University Press.

Rose, M. (2004): "Biological immortality". En The scientific conquest of death : essays on infinite lifespans. 1a. ed., Buenos Aires: Libros En Red.

Shostak, S. (2006): The Evolution of Death: Why We Are Living Longer. SUNY series in Philosophy and Biology. Albany, NY: State University of New York.
Vargas, E. (2009): “El problema del tiempo biológico en Zubiri". Philosophica, volumen 35, Pontificia Universidad Católica de Valparaíso, 229-258.

Weismann, A. (1889): "The duration of life". En Essays upon Heredity and kindred biological problems, Oxford: At the Clarendon Press.

Zubiri, X. (2006): Tres dimensiones del ser humano: Individual, Social, Histórica. Madrid: Alianza.

Zubiri, X. (2008): Espacio, Tiempo, Materia. Nueva edición. Madrid: Alianza. 